\title{
PENERAPAN METODE LSB-2 UNTUK MENYEMBUNYIKAN CIPHERTEXT PADA CITRA DIGITAL
}

\author{
Taronisokhi Zebua
}

\author{
Dosen Tetap Program Studi S1 Teknik Informatika STMIK Budi Darma Medan. \\ Jl. Sisingamangaraja No. 338 Sp. Limun Medan \\ www.stmik-budidarma.ac.id // Email : taronizeb@gmail.com
}

\begin{abstract}
ABSTRAK
Algoritma triangle chain cipher adalah salah satu algoritma kriptografi klasik yang dikembangkan untuk menghasilkan ciphertext dari pesan asli (plaintext). Proses enkripsi dan enkripsi pesan rahasia dengan algoritma triangle chain cipher dilakukan secara ganda (double) berdasarkan perkalian nilai kunci dan faktor pengali sehingga ciphertext yang dihasilkan sangat jauh berbeda dari teks pesan asli. Metode Least Significant Bit-2 (LSB-2) merupakan modifikasi dari metode LSB yang umumnya digunakan untuk menyembunyikan pesan rahasia pada media lain (steganografi). Metode LSB-2 bekerja dengan konsep menukarkan bit ke 8-2 (bit 6) dari setiap elemen warna pixel gambar yang dijadikan sebagai medium dengan bit pesan rahasia. Penelitian ini membahas kombinasi metode LSB-2 dengan algoritma triangle chain cipher untuk menghasilkan stegano image. Pesan rahasia yang telah dienkripsi berdasarkan algoritma triangle chain disembunyikan dalam citra digital berdasarkan metode LSB-2 sehingga pesan rahasia tidak mudah diketahui dan dipecahkan oleh orang lain. Citra cover yang digunakan dalam penelitian ini adalah gambar berwarna dan berjenis bitmap (.bmp) dan aplikasi yang digunakan untuk menguji dan membangun sistem adalah aplikasi visual studio 2008.
\end{abstract}

Kata Kunci : kriptograf, triangle chain cipher, steganografi, lsb-2

\section{Pendahuluan}

Teknik yang umum digunakan untuk meng-amankan pesan rahasia dari orang-orang yang tidak berhak adalah teknik kriptografi. Teknik ini merupakan proses pengubahan setiap karakter dari teks asli (plaintext) menjadi karakter lain (ciphertext). Namun penerapan teknik kriptografi juga masih memiliki kelemahan, salah satunya adalah munculnya kecurigaan yang cepat dari orang lain bahwa informasi tersebut bersifat rahasia, sehingga menimbulkan niat untuk mengetahui informasi yang sebenarnya.

Teknik lain adalah teknik steganografi, yaitu salah satu teknik yang digunakan untuk menyembunyikan pesan rahasia pada objek lain misalnya citra digital, audio dan video. Teknik steganografi pesan rahasia pada citra digital dilakukan dengan menukarkan bit tertentu dari citra digital penampung pesan dengan bit pesan rahasia yang akan disembunyikan. Metode Least Significant Bit (LSB) merupakan metode yang paling umum digunakan untuk menyembunyikan pesan rahasia ke dalam media citra, namun pemanfaatan metode ini masing sangat mudah dipecahkan oleh orang lain yaitu dengan menukar bit terakhir (bit ke delapan dari elemen warna citra) sehingga pesan yang tersebunyi dapat dihancurkan.

Metode LSB-2 merupakan hasil modifikasi metode LSB yang bekerja dengan konsep menukarkan bit ke 8-2 (bit ke-6) dari setiap elemen warna pixel citra digital yang menjadi citra penampung dengan setiap bit pesan rahasia yang akan disembunyikan.

Algoritma Triangle Chain Cipher (TCC) merupakan salah satu hasil modifikasi dari algoritma kriptografi klasik yang melakukan enkripsi dan dekripsi secara berantai (ganda) sehingga menghasilkan cipher teks yang sangat jauh berbeda dengan pesan aslinya.

Kombinasi antara dua teknik ini (algoritma triangle chain cipher dan LSB-2) mampu meningkatkan keamanan dari pesan rahasia dari tindakan-tindak orang lain yang tidak bertanggung-jawab.

\section{Tujuan Penelitian}

Tujuan Penelitian yang dilakukan adalah :

1. Mendapatkan ciphertext dari plaintext atau sebaliknya dengan algoritma Triangle Chain Cipher.

2. Menyembunyikan dan mengekstaksi ciphertext pada citra digital dengan metode Least Significant Bit-2.

3. Mendapatkan nilai perbandingan rasio antara citra asli dengan citra hasil (stegano image) setelah ciphertext disembunyikan.

4. Menjaga dan meningkatkan keamanan informasi yang bersifat penting/rahasia dari tindakan cryptoanalysis dan staganalysis.

\section{Landasan Teori}

Pembahasan masalah dalam penelitian ini didasari oleh teori-teoritis yang relevan dengan judul penelitian.

\subsection{Kriptografi}

\section{A. Aspek Kriptografi}

Ada beberapa aspek kriptografi adalah [2] :

1. Confidentiality (Kerahasiaan)

Pesan rahasia dapat diakses oleh orang yang benarbenar memiliki hak akases untuk mengaksesnya.

2. Integrity (Integritas)

Hak akses untuk melakukan pengubahan terhadap data harus benar-benar terjaga. 
3. Auhentication (Otentikasi)

Identifikasi terhadap kebenaran pesan, pemiliki maupun kebenaran terhadap hak akses pesan

4. Non-Repudiation

Layanan untuk mencegah terjadinya penyangkalan terhadap pengiriman maupun penerimaan pesan.

\section{B. Algoritma Triangle Chain Cipher}

Algoritma kriptografi triangle chain cipher atau umumnya dikenal dengan sebutan rantai segitiga merupakan salah satu pengembangan dari algoritma kriptografi klasik untuk menghasilkan ciphertext. Algoritma kriptogarfi Tiangle Chain Cipher melakukan proses enkripsi terhadap plainteks secara berantai atau ganda [4].

Kekuatan cipher ini terletak pada kunci yaitu nilai integer yang menunjukkan pergeseran karakter-karakter sesuai dengan operasi pada caesar cipher. Kekuatan kedua terletak pada barisan bilangan-bilangan yang berfungsi sebagai pengali dengan kunci.

Secara matematis, pola enskripsi dan dekripsi dengan algoritma triangle chain cipher dapat digambarkan dengan matriks $\mathrm{N}$ x $\mathrm{N}$ dengan $\mathrm{N}$ merupakan panjang plaintext yang akan dienskripsi dan operasi pada alfabet ASCII.

Operasi matriks untuk proses enkripsi pada algoritma triangle chain cipher sebagai berikut [2] :

\section{Proses Enkripsi Plainteks:}

1. Matriks Enkripsi Segitiga Pertama

Untuk baris ke-1 :

$\mathrm{M}_{1 \mathrm{j}}=\mathrm{P}[\mathrm{j}]+\left(\mathrm{K}^{*} \mathrm{R}[1]\right) \bmod 255$

untuk baris ke-2 dan selanjutnya untuk nilai $\mathrm{j} \geq \mathrm{i}$ :

$\mathrm{M}_{\mathrm{ij}}=\mathrm{M}_{(\mathrm{i}, \mathrm{j})}+(\mathrm{K} * \mathrm{R}[\mathrm{i}]) \bmod 255$, sehingga nilai

ciphertext yang diperoleh adalah :

$\mathrm{M}_{\mathrm{ij}}=[\mathrm{j},(\mathrm{N}+\mathrm{j})-\mathrm{n}]$.

2. Matriks Enkripsi Segitiga Kedua

Nilai $P$ diperoleh dari nilai Mij pada $\mathrm{i}=\mathrm{j}$

Untuk baris ke-1 :

$\left.\mathrm{M}_{1 \mathrm{j}}=\mathrm{P}[\mathrm{j}]+\left(\mathrm{K}^{*} \mathrm{R}[1]\right)\right) \bmod 255$

untuk baris ke 2 dan selanjutnya untuk nilai $\quad \mathrm{j} \leq$ $(\mathrm{N}+1)-\mathrm{i}$ :

$\left.\mathrm{M}_{\mathrm{ij}}=\mathrm{M}_{(\mathrm{i}, \mathrm{j})}+(\mathrm{K} * \mathrm{R}[\mathrm{i}])\right) \bmod 255$, sehingga nilai

cipherteks yang diperoleh adalah :

$\mathrm{M}_{\mathrm{ij}}=[(\mathrm{N}-\mathrm{j})+1, \mathrm{j}]$.

Keterangan :

$\mathrm{P}=$ Plainteks ; N=Jumlah Karakter Plainteks;

$\mathrm{M}=$ Matriks penampung hasil penyandian

$\mathrm{K}=$ Kunci; $\mathrm{R}=$ Row (baris perkalian faktor pengali dengan kunci); $\mathrm{i}=$ Index faktor pengali; $\mathrm{j}=$ Index karakter plaintext; Nilai $\mathrm{R}=\mathrm{M} ; \mathrm{J}=\mathrm{R} ; \mathrm{i}=\mathrm{R}$

\section{Proses Dekripsi Ciphertext :}

Proses denskripsi merupakan kebalikan dari proses enkripsi. Operasi matriks untuk proses dekripsi adalah sebagai berikut:

1. Matriks dekripsi segitiga pertama operasinya merupakan kebalikan dari matriks enskripsi, jadi operasi ini kebalikan operasi matriks enkripsi segitiga kedua. Nilai $\mathrm{C}$ merupakan tabel dari ciphertext dengan panjang $\mathrm{N}$ yaitu $\mathrm{C}[\mathrm{N}]$.

Mencari baris ke-1 :

$\mathrm{M}_{1 \mathrm{j}}=\mathrm{C}[\mathrm{j}]-(\mathrm{K} * \mathrm{R}[1]) \bmod 255$

untuk baris ke-2 dan selanjutnya untuk nilai $\mathrm{j} \geq \mathrm{i}$ :

$\mathrm{M}_{\mathrm{ij}}=\mathrm{C}_{(\mathrm{i}, \mathrm{j})}-(\mathrm{K} * \mathrm{R}[\mathrm{i}]) \bmod 255$

Nilai ciphertext yang diperoleh adalah :

$\mathrm{M}_{\mathrm{ij}}=[\mathrm{j},(\mathrm{N}+\mathrm{j})-\mathrm{n}]$.

2. Matriks dekripsi segitiga kedua

Baris pertama berlaku formula, dengan nilai $\mathrm{i}=\mathrm{j}$

Untuk baris ke-1 :

$\left.\mathrm{M}_{1 \mathrm{j}}=\mathrm{C}[\mathrm{j}]-\left(\mathrm{K}^{*} \mathrm{R}[1]\right)\right) \bmod 255$

untuk baris ke 2 dan selanjutnya untuk nilai

$\mathrm{j} \leq(\mathrm{N}+1)-\mathrm{i}$ :

$\left.\mathrm{M}_{\mathrm{ij}}=\mathrm{M}_{(\mathrm{i}, \mathrm{j})}-\left(\mathrm{K}^{*} \mathrm{R}[\mathrm{i}]\right)\right) \bmod 255$, sehingga nilai

cipherteks yang diperoleh adalah :

$\mathrm{M}_{\mathrm{ij}}=[(\mathrm{N}-\mathrm{j})+1, \mathrm{j}]$.

Keterangan : $\mathrm{C}=$ Ciphertext

\subsection{Steganografi}

\section{A. Teknik Penyembunyian dan Ekstrasi Pesan}

Sebagai contoh 3 buah pixel (sembilan bytes) citra digital 24 bit dijadikan sebagai medium pesan yang akan disembunyikan dengan pesan teks rahasia adalah karakter T dengan nilai RGB sebagai berikut :
11110101
00010110
10101010
11000100
11111001
00000001
00000001
11110001
00011101

karakter $\mathrm{T}$ dalam biner adalah 01010100, maka dengan menggunakan metode LSB, maka akan dihasilkan citra hasil dengan urutan bit akhir sebagai berikut :

$\begin{array}{lll}1111010 \underline{0} & 0001011 \underline{\underline{1}} & 1010101 \underline{0} \\ 1100010 \underline{\underline{1}} & 1111100 \underline{\underline{0}} & 0000000 \underline{\underline{0}} \\ 0000000 \underline{\underline{0}} & 1111000 \underline{\underline{1}} & 00011101\end{array}$

Ekstraksi data dilakukan dengan cara memisahkan pesan dari wadah penampung dan tahap-tahap ekstraksi yang dilakukan hanya diizinkan untuk diketahui oleh orang yang dituju. Apabila metode penyembunyian pesan pada wadah dilakukan dengan LSB, maka teknik ekstraksi dilakukan dengan cara yang sama pula yaitu mengumpulkan kembali bit-bit yang tersimpan pada bit akhir setiap byte pixel wadah penampung kemudian bit-bit tersebut dikonversikan menjadi teks yang memiliki arti seperti teks aslinya. 


\section{B. Metode Least Significant Bit-2}

Metode ini menukar bit pixel medium penampung yang dengan setiap bit pesan yang akan disembunyikan. Apabila pada LSB menukarkan bit akhir (bit ke-8) maka pada LSB-2 akan menukarkan bit ke-8 dikurangi dengan 2 (nilai LSB - 2) atau sama dengan bit ke-6 [7].

$\begin{array}{lll}11110101 & 00010110 & 10101010 \\ 11000100 & 11111001 & 00000001 \\ 00000001 & 11110001 & 00011101\end{array}$

karakter $\mathrm{T}$ dalam biner $=01010100$, maka akan dihasilkan citra hasil dengan urutan bit akhir sebagai berikut :

$\begin{array}{lll}11110 \underline{0} 01 & 00010 \underline{1} 10 & 10101 \underline{\underline{0}} 10 \\ 11000 \underline{\underline{1}} 00 & 11111 \underline{\underline{0}} 01 & 00000 \underline{\underline{0}} 01 \\ 00000 \underline{0} 01 & 11110 \underline{\underline{1}} 01 & 00011101\end{array}$

Uraian contoh penerapan modifikasi metode least significant bit di atas, dapat disimpulkan bahwa bit-bit yang ditukarkan tidak lagi berada pada bit akhir byte pixel, sehingga dapat mempersulit para penyusup untuk mengungkap pesan rahasia yang ada di dalam medium pesan.

\section{Metodologi Penelitian}

Penelitian ini difokuskan pada pengkombinasian teknik steganogafi dan kriptografi dalam mengaman-kan pesan rahasia. Model yang digunakan dalam proses enkripsi dan dekripsi pesan rahasia adalah algoritma triangle chain cipher, sedangkan untuk menyembunyikan ciphertext ke dalam citra digital dilakukan berdasarkan modifikasi metode Least Significant Bit-2 (LSB-2).

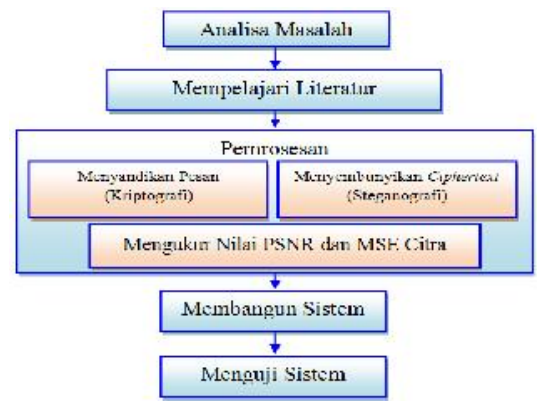

\section{Gambar 1 : Kerangka Kerja Penelitian}

\section{Proses Analisa dan Hasil}

Seperti yang telah diuraikan di atas bahwa secara garis besar proses yang dilakukan meliputi 3 kegiatan utama, yaitu proses enkripsi terhadap pesan rahasia yang akan disembunyikan, proses penyembunyian dan proses ekstraksi pesan rahasia.

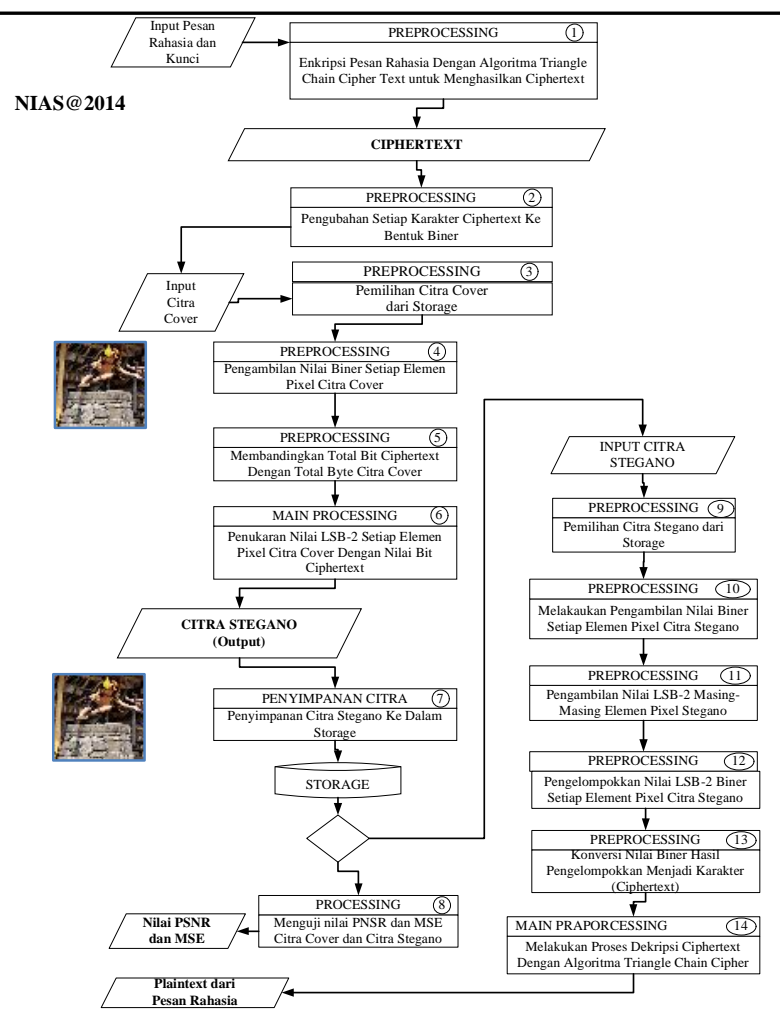

Gambar 2 : Skema Proses Dalam Penelitian A. Proses Penyembunyian Ciphertext : INPUT :

- Pesan Rahasia : NIAS @ 2014

- Citra Digital

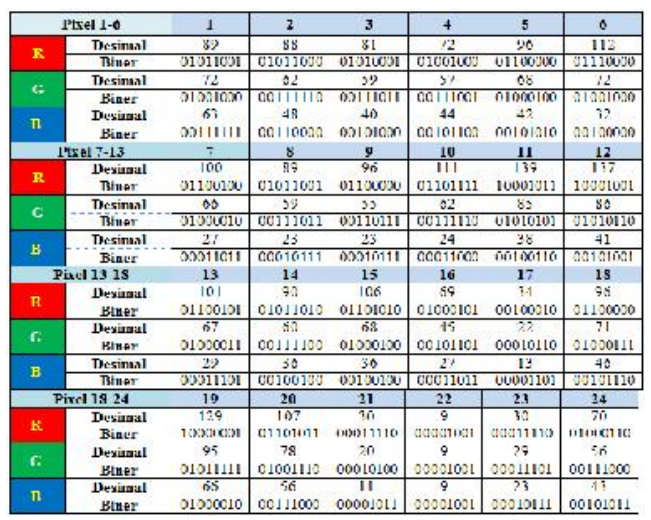

\section{Gambar 3 : Citra Biner Pixel Citra Cover}

\section{PROSES :}

a. Proses Enkripsi Pesan

- Proses Enkripsi Segitiga Pertama : untuk Baris Pertama :

$$
\begin{aligned}
& C_{1}-\left(18-\left(j^{*} 1\right) \bmod 25 s-81 \rightarrow Q \quad c_{t}-\left(20+\left(3^{*} 1\right)\right) \bmod 25 s-51 \rightarrow\right. \\
& C_{2}=\left(73-\left(3^{*} 1\right)\right) \bmod 255=76 \rightarrow \mathrm{L} \quad C_{i}=\left(48+\left(3^{*} 1\right)\right) \operatorname{med} 255=51 \rightarrow 3
\end{aligned}
$$

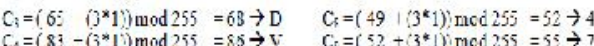

$$
\begin{aligned}
& \left.C_{j}=\left(64-\left(j^{\wedge} 1\right)\right)_{\bmod } 2 y\right)=0: \rightarrow \mathrm{C} \quad \text { Hasil Liphar pada proses baris pertama } \\
& \text { QLDVC5347 }
\end{aligned}
$$

Hasil cipher yang didapatkan pada baris pertama akan digunakan pada proses enciphering untuk baris kedua. 
Proses untuk menghasilkan cipher pada baris kedua :

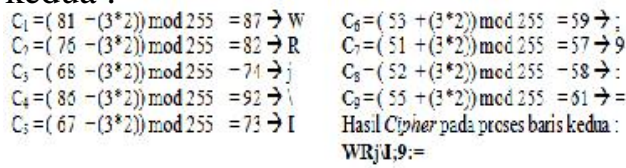

Hasil ini akan digunakan untuk proses enkripsi baris ke-3 dan seterusnya.

- Proses Enkripsi Segitiga Kedua untuk baris pertama :

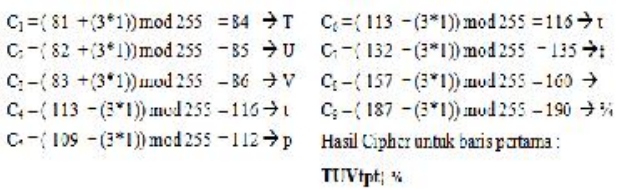

untuk baris kedua dan seterusnya :

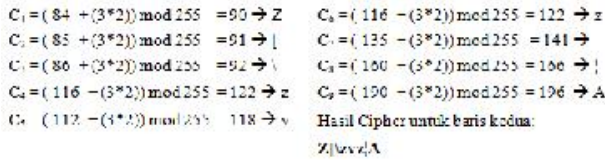

Hasil ini akan digunakan untuk proses enkripsi baris ke-3 dan seterusnya.

Formula yang digunakan untuk menentukan ciphertext dari proses enkripsi segitiga kedua adalah $\mathrm{M}_{\mathrm{ij}}=[(\mathrm{N}-\mathrm{j})+1, \mathrm{j}]$.

Ciphertext yang dihasilkan pada proses enkripsi segitiga kedua inilah yang menjadi ciphertext akhir.

b. Proses Perbandingan Total Bit Pixel Citra dengan Total bit Ciphertext

Penyembunyian pesan rahasia berhasil apabila seluruh total bit ciphertext tidak lebih besar dari total bit citra cover. Apabila total bit ciphertext > total bit citra cover, akan menyebabkan sebagian dari bit-bit tersebut tidak dapat disimpan pada citra cover, sehingga pesana rahasia tidak dapat diambil kembali pada saat proses ekstraksi dilakukan.

c. Proses Penyisipan

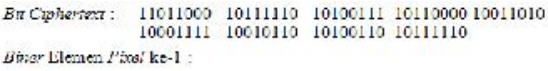

Braphertaz: 110110001011110101001111011000010011010

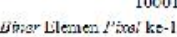

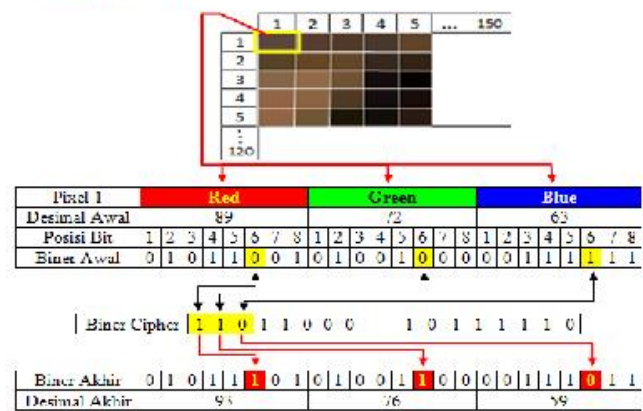

Gambar 4 : Penukaran Bit ke-6 Elemen Warna Pixel ke-1

\section{OUTPUT :}

1. Output Proses Enkripsi

a. Enkripsi Segitiga Pertama

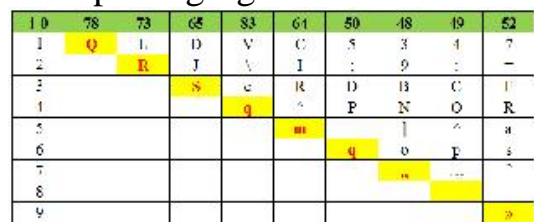

b. Enkripsi Segitiga Kedua

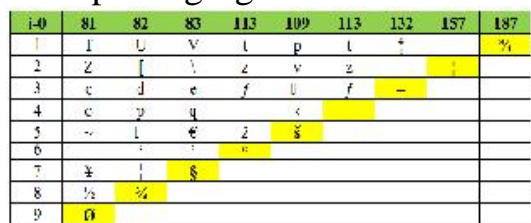

Karakter plaintext diambil dari hasil proses enkripsi segitiga kedua yaitu $\emptyset^{3} / 4 \S^{\circ} \check{\mathbf{s}}-i^{i} / 4$

\section{Proses Perbandingan Ukuran Citra Cover dengan Ciphertext}

Berdasarkan ukuran citra cover yang digunakan sebagai sampel diperoleh bahwa :

Total pixel citra $=$ width $\mathrm{x}$ height

$$
\begin{aligned}
& =120 \text { pixel } \mathrm{x} 150 \text { pixel } \\
& =18.000 \text { pixel }
\end{aligned}
$$

setiap pixel citra bitmap disusun oleh 3 elemen warna yaitu red, green dan blue dan setiap satu elemen warna pixel terdiri dari 8 bit, sehingga setiap satu pixel terdiri dari 24 bit, maka :

Total bit Citra $=$ Total Pixel Citra $\mathrm{x} 3$

$$
\begin{aligned}
& =18.000 \times 24 \\
& =432.000 \mathrm{bit}
\end{aligned}
$$

Berdasarkan perhitungan di atas, dapat kita simpulkan bahwa total bit citra cover lebih besar dibandingkan dengan total bit ciphertext (72 bit), sehingga proses penyembunyian ciphertext dapat dilakukan dengan menggunakan citra sampel.

3. Output Proses Penyembunyian Ciphertext Output akhir dari proses 1 dan 2 adalah Citra Stegano

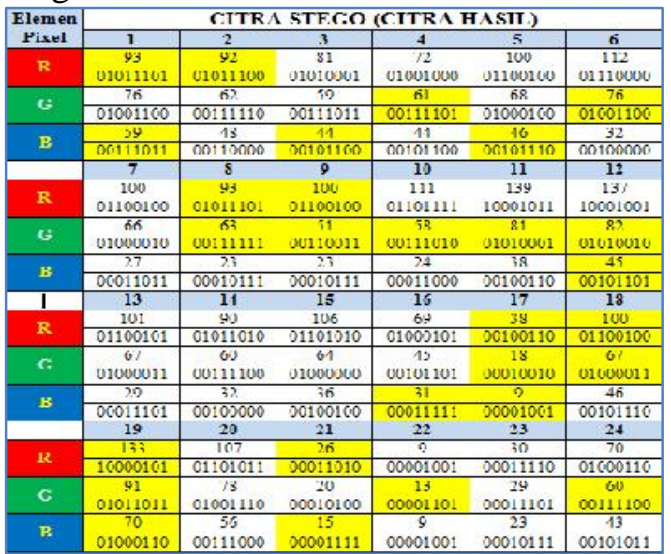

Gambar 5 : Nilai Biner Pixel Elemen Warna Citra Stegano 


\section{B. Proses Ekstraksi Ciphertext}

Proses ekstraksi pesan rahasia yang telah disembunyikan pada citra digital, dilakukan berdasarkan metode LSB-2 yaitu dengan mengambil nilai LSB-2 dari citra stegano (citra penampung pesan). Total LSB-2 dari citra stegano yang diambil adalah sesuai dengan total bit ciphertext pesan rahasia yang telah disembunyikan sebelumnya.

Biner-biner terebut dikelompokkan menjadi 8 bit setiap kelompok, agar karakter dapat ciphertext dapat dibentuk $(1$ karakter $=8$ bit $)$. Kelompok biner tersebut kemudian dikonversikan ke bentuk karakter, sehingga didapatkan ciphertext yang telah disembunyikan.

Proses selanjutnya adalah melakukan proses dekripsi ciphertext berdasarkan algoritma triangle chain cipher, sehingga pesan asli didapatkan.

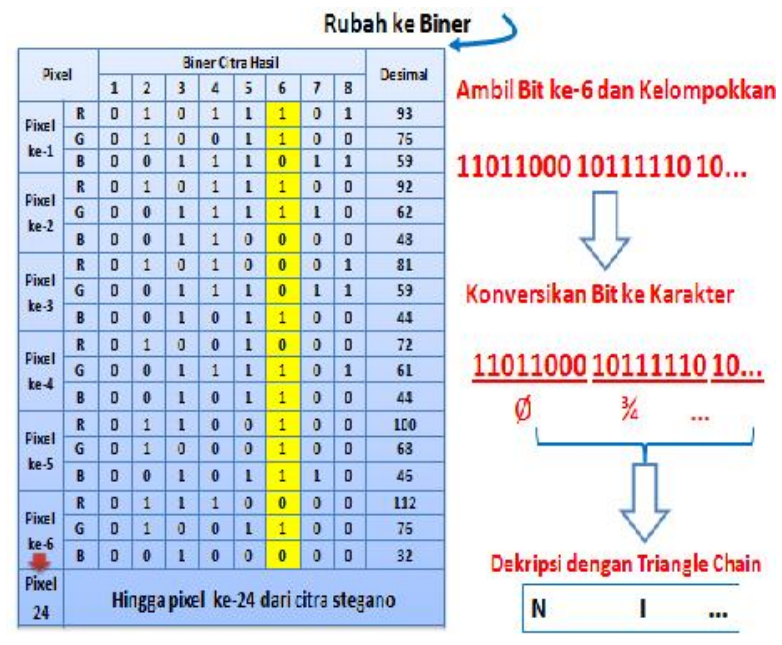

\section{Gambar 6 : Proses Pengambilan dan Konversi Nilai LSB-2 untuk Mendapatkan Pesan Rahasia}

\section{Hasil Pengujian}

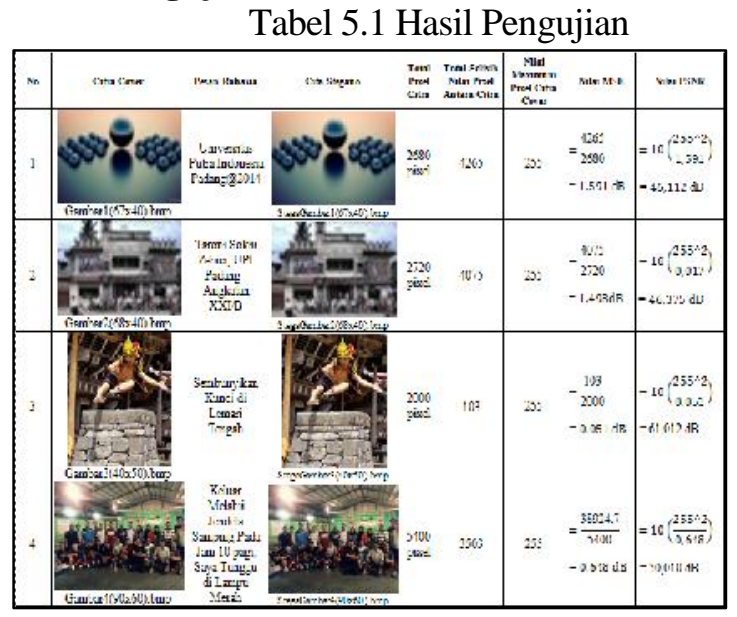

\section{Kesimpulan}

Kesimpulan yang didapatkan dari penelitian, yaitu :
1. Kombinasi antara teknik kriptografi dengan teknik steganografi mampu memberikan tingkat keamanan pesan rahasia yang rumit dipecahkan.

2. Penukaran LSB-2 elemen warna pixel citra mengakibatkan nilai intensitas pixel bertambah menjadi 4 bit apabila nilai elemen warna pixel yang ditukar dari 0 menjadi 1 dan akan berkurang 4 bit apabila nilai elemen warna yang ditukar dari 1 menjadi 0 . Apabila bit yang ditukarkan sama, maka tidak terjadi perubahan nilai intensitas elemen warna pixel.

3. Pengujian tingkat kemiripan citra cover dengan citra stegano dilakukan dengan menghitung nilai Peak Signal to Noise Ratio (PSNR) yang merupakan rasio kemiripan citra, sedangkan untuk mengukur tingkat error dari citra cover dilakukan dengan menghitung nilai Mean Square Error dari citra cover.

\section{Saran}

Saran-saran dalam penelitian ini adalah :

1. Perhatian terhadap pengamanan setiap pesan penting harus lebih ditingkatkan agar setiap informasi penting tidak disalahgunakan oleh orang-orang yang tidak berkepentingan.

2. Algoritma triangle chain cipher dapat dikembangkan penerapannya pada pengamanan audio atau video.

3. Semakin besar nilai LSB yang diganti akan berpengaruh besar terhadap perubahan nilai pixel warna.

\section{Daftar Pustaka}

[1] Ariyus Dony (2008). "Pengantar Ilmu Kriptografi". $1^{\text {st }}$. Andi. hlm 9-44

[2] Zebua Taronisokhi (2013). “Analisa dan Implementasi Algoritma Triangle Chain Pada penyandian Record Database”. Pelita Informatika Budi Darma. Volume III Nomor 2. hlm 37-49.

[3] Garg Rohit (2012). "Comparison of Lsb \& Msb Based Steganography In Gray-Scale Images". International Journal of Engineering Research \& Technology (IJERT). Vol. 1 Issue 8. hlm 1-6

[4] Mesran dan Darmawati (2012). "Aplikasi Pengamanan Data Teks Pada Citra Bitmap Dengan Menerapkan Metode Least Significant Bit (LSB)". Pelita Informatika Budi Darma. Volume III Nomor 2. hlm 5-9

[5] Nath Joyshree et al (2011) "Advanced Steganographic Approach for Hiding Encrypted Secret Message in $L S B, L S B+1, L S B+2$ and $L S B+3$ Bits in Non standard Cover Files”. International Journal of Computer Applications. Volume 14 No. 7. hlm 31-35

[6] Mukharom Edisuryana et al (2013), "Aplikasi Steganografi Pada Citra Berformat Bitmap Dengan Menggunakan Metode End Of File”. TRANSIENT. Volume 2 Nomor 3

[7] Yudhi Andrian (2013). "Modifikasi Metode Least Significant Bit (LSB) Pada Steganografi Citra 
Digital”. SNIKOM 2013 FIKOM-Universitas

Methodist Indonesia. hlm 274-279

[8] Putra Darma (2010). "Pengolahan Citra Digital". $1^{\text {st }}$. Andi. hlm 19-38

[9] RD Kusumanto (2011). "Pengolahan Citra Digital Untuk Mendeteksi Obyek Menggunakan Pengolahan Warna Model Normalisasi RGB”. Semantik 2011.

[10] Rahul Joshi et al (2013). "Image Steganography With LSB". International Journal of Advanced Research in Computer Engineering \& Technology (IJARCET) Volume 2 Issue 1. hlm 228-229

[11] Soniya Vijayakumar (2011). "Image Steganography Based on Polynomial Functions". Journal of Global Research in Computer Science. Volume 2. Nomor 3. hal 13-15

[12] Ghazali Moenandar Male et al (2012). “Analisa Kualitas Citra Pada Steganografi untuk Aplikasi EGovernment”. Prosiding Seminar Nasional Manajemen Teknologi XV. hlm 1-9

[13] Novi Dian Nathasia et all (2011). "Penerapan Teknik Kriptografi Stream Cipher untuk Pengamanan Basis Data”. Jurnal Basis Data, IT Research Center. Vol 6. No. 1

[14] Anandia Zelvina et all (2012). "Perancagan Aplikasi Pembelajaran Kriptografi Kunci Publik ElGamal untuk Mahasiswa”. Jurnal Dunia Teknologi Informasi Vol. 1, No. 1, (2012). Hal. 5662 